\title{
North Korean refugee doctors' preliminary examination scores
}

\author{
Sung Uk Chae', Jeong Hee Yang', Joon Seop Hyun', June Hee Kim¹ and Seok Hoon Kang',2 \\ ${ }^{1}$ Department of Family Medicine, Kangwon National University Hospital, and ${ }^{2}$ Department of Medical Education, \\ Kangwon National University School of Medicine, Chuncheon, Korea
}

Purpose: Although there have been studies emphasizing the re-education of North Korean (NK) doctors for post-unification of the Korean Peninsula, study on the content and scope of such re-education has yet to be conducted. Researchers intended to set the content and scope of re-education by a comparative analysis for the scores of the preliminary examination, which is comparable to the Korean Medical Licensing Examination (KMLE).

Methods: The scores of the first and second preliminary exams were analyzed by subject using the Wilcoxon signed rank test. The passing status of the group of NK doctors for KMLE in recent 3 years were investigated. The multiple-choice-question (MCQ) items of which difficulty indexes of NK doctors were lower than those of South Korean (SK) medical students by two times of the standard deviation of the scores of SK medical students were selected to investigate the relevant reasons.

Results: The average scores of nearly all subjects were improved in the second exam compared with the first exam. The passing rate of the group of NK doctors was $75 \%$. The number of MCQ items of which difficulty indexes of NK doctors were lower than those of SK medical students was $51(6.38 \%)$. NK doctors' lack of understandings for Diagnostic Techniques and Procedures, Therapeutics, Prenatal Care, and Managed Care Programs was suggested as the possible reason.

Conclusion: The education of integrated courses focusing on Diagnostic Techniques and Procedures and Therapeutics, and apprenticeship-style training for clinical practice of core subjects are needed. Special lectures on the Preventive Medicine are likely to be required also.

Key Words: Foreign medical graduates, Clinical competency, Democratic People's Republic of Korea, Refugees

\section{Introduction}

The recent international situation surrounding the Korean Peninsula is giving a signal that the two Koreas could be unified in the near future [1]. However, South and North Korea have evolved in different cultures and legal boundaries maintaining a hostile relation since the ceasefire agreement in 1953. Therefore, after unification, the healthcare system of the Korean Peninsula is likely to face severe problems like Yemen, Vietnam, and Germany, which were transformed to system integration countries through political unification [2].

The health care systems of North Korea collapsed along with the downfall of global communist societies in the 1990s and were followed by great famine known as "Arduous March" [3]. Considering the characteristics of medical education that traditionally put emphasis on the clinical clerkship in the teaching hospitals [4], doubt is cast on the clinical competency of North Korean doctors who
Received: May 28, 2016 • Revised: July 22, 2016 • Accepted: August 8, 2016 Corresponding Author: Seok Hoon Kang (http://orcid.org/0000-0002-2881-8774) Department of Medical Education, Kangwon National University School of Medicine, 1 Gangwondaehak-gil, Chuncheon 24341, Korea

Tel: +82.33.258.9206 Fax: +82.504.477.4271 email: kingla@kangwon.ac.kr
Korean J Med Educ 2016 Dec; 28(4): 373-380.

https://doi.org/10.3946/kjme.2016.42

eISSN: 2005-7288

(C) The Korean Society of Medical Education. All rights reserved. This is an open-access article distributed under the terms of the Creative Commons Attribution Non-Commercial License (http:// creativecommons.org/licenses/by-nc/3.0/), which permits unrestricted non-commercial use, distribution, and reproduction in any medium, provided the original work is properly cited. 
were taught and trained under such a harsh condition.

Despite limitations on data collection, a few studies on the restoration of medical system and the utilization of medical personnel of North Korea after unification are being published by South Korean scholars [1,5]. They invariably address the need for re-education of North Korean doctors. However, studies that can answer specific questions such as "On which fields and to what extent the education is planned?" have not yet been conducted.

In 2013, Kangwon National University School of Medicine (KNUSM), signed an memorandum of understanding (MOU) with Hanawon, a government-affiliated organization of the Minister of Unification, whose aim is providing education for social adaptation of North Korean refugees, and provided a so called "profession transition course for doctors" for 9 months to help 12 North Korean refugee doctors prepare for Korean Medical Licensing Examination (KMLE). The 10 North Korean refugee doctors who fully participated in this training took the preliminary examination twice as a summary test for special education under the same exam conditions as the 4th year medical students of KNUSM.

The preliminary examination is known as the most similar examination to the written test of KMLE in the test format and its scores are known to be closely associated with those of the written test of KMLE [6]. Therefore, an analysis on the scores of the group of North Korean refugee doctors in the preliminary examination can contribute to setting the content and scope of re-education for them, and furthermore, it could help measure their practical clinical competency.

\section{Subjects and methods}

The subjects of this study were 10 North Korean refugee doctors who got through with preparatory training for the
KMLE at KNUSM in 2013 and 46 of the 4th year medical students of KNUSM in the same year. Both two groups took preliminary examinations made by Korea Medical Education Assessment consortium that nearly all medical schools in South Korea were participating in.

The preliminary examination of which official title was 'Clinical Medical Science Comprehensive Examination' consisted of 400 multiple-choice-question items (MCQ items), which were designed according to the same principles for the written test of KMLE. All items can be categorized as Internal Medicine, General Surgery, Obstetrics \& Gynecology, Pediatrics, Psychiatry, Preventive Medicine, Medical Health Legislation, etc. according to the subjects. The first preliminary examination was taken 6 months after the start of the transition course for doctors and the second examination was taken 1 month just before KMLE. All scores of preliminary examination were converted to a $100-$ point scale, as in the written test of the KMLE.

The scores of the group of North Korean doctors and the group of South Korean students in the first and second preliminary examinations were analyzed by each subject using the Wilcoxon signed rank test. The passing status of the group of North Korean doctors for the KMLE in recent 3 years was determined.

The difficulty indexes of the entire MCQ items in the first and second preliminary examinations were calculated for the group of North Korean doctors and the group of South Korean medical students, respectively. In order to determine the reasons for the difference in the difficulty indexes between North Korean doctors and South Korean medical students, a doctor who experienced both South Korean and North Korean medical schools as a medical student analyzed MCQ items of which difficulty indexes of North Korean doctors were lower than those of South Korean medical students by two times of the standard deviation of the scores of 
South Korean medical students.

For statistics, the R Foundation for statistical computing, $\mathrm{R}$ version 3.2.2 was used and the significance level was set to 0.01 and 0.05 .

\section{Results}

The average age of the group of North Korean refugee doctors was 39.8 years old for men and 42.8 years old for women, which was about 10 years apart from the 4th year students of KNUSM, whose average age was 30.9 years old for men and 30.2 for women. The North Korean refugee doctors worked for 12.6 years on average as doctors and escaped from North Korea when they were 37.2 years old on average (Table 1).

In most subjects, the average scores of the group of South Korean medical students were higher than 60 points in the first exam, which was the passing mark for the KMLE, and the average scores of nearly all subjects were improved in the second exam compared with the first exam. On the other hand, the average scores of the group of North Korean doctors were 60 points or less in both the first and second exams, and although the average scores of the second exam were improved in all subjects, it was statistically significant only in the subjects of General Surgery, Obstetrics, Pediatrics, and Medical Health Legislation (Table 2).

Table 1. Demographic Factors of Research Objects

\begin{tabular}{|c|c|c|c|c|}
\hline \multirow{2}{*}{ Variable } & \multicolumn{2}{|c|}{ NK doctor $(n=10)$} & \multicolumn{2}{|c|}{ SK medical student $(n=46)$} \\
\hline & Male $(n=4)$ & Female $(n=6)$ & Male $(n=24)$ & Female $(n=22)$ \\
\hline Age (yr) & $39.8 \pm 9.5$ & $42.8 \pm 9.3$ & $30.9 \pm 3.3$ & $30.2 \pm 2.6$ \\
\hline Physician experience in NK (yr) & $9.5 \pm 6.6$ & $14.7 \pm 7.1$ & - & - \\
\hline Age at escape from NK (yr) & $37.0 \pm 8.0$ & $37.3 \pm 7.2$ & - & - \\
\hline
\end{tabular}

Data are presented as mean \pm standard deviation.

NK: North Korea, SK: South Korea.

Table 2. Wilcoxon Signed Rank Test Result between First and Second Preliminary Examination Scores among NK Doctors and SK Medical Students

\begin{tabular}{|c|c|c|c|c|c|c|c|c|}
\hline \multirow{3}{*}{ Subject (no. of items) } & \multicolumn{4}{|c|}{ NK doctor $(n=10)$} & \multicolumn{4}{|c|}{ SK medical students $(n=46)$} \\
\hline & \multicolumn{2}{|c|}{ First exam } & \multicolumn{2}{|c|}{ Second exam } & \multicolumn{2}{|c|}{ First exam } & \multicolumn{2}{|c|}{ Second exam } \\
\hline & Mean $^{\text {al }}$ & SD & Mean $^{\text {al }}$ & SD & Mean $^{\text {al }}$ & SD & Mean $^{\text {al }}$ & SD \\
\hline Internal Medicine (143) & 39.7 & 8.6 & 42.4 & 10.4 & 62.6 & 7.3 & $73.5^{\mathrm{bl}}$ & 5.4 \\
\hline General Surgery (48) & 41.5 & 11.4 & $51.0^{c 1}$ & 10.1 & 63.6 & 8.6 & $75.6^{b)}$ & 5.7 \\
\hline Obstetrics $(26 / 30)^{d}$ & 42.3 & 13.0 & $46.0^{c 1}$ & 11.0 & 73.2 & 8.0 & $71.2^{\mathrm{bl}}$ & 8.1 \\
\hline Gynecology $(24 / 20)^{d /}$ & 36.7 & 8.5 & 39.5 & 10.9 & 66.2 & 9.5 & $67.0^{\mathrm{bl}}$ & 11.9 \\
\hline Pediatrics (48) & 38.5 & 13.0 & $49.2^{c 1}$ & 12.6 & 59.1 & 9.0 & $76.9^{\mathrm{bl}}$ & 6.9 \\
\hline Psychiatry (35) & 38.9 & 10.0 & 39.7 & 9.1 & 61.0 & 9.3 & $64.7^{\mathrm{cl}}$ & 10.3 \\
\hline Preventive Medicine (24) & 25.0 & 5.5 & 25.8 & 8.5 & 51.4 & 13.7 & $63.3^{\mathrm{bl}}$ & 10.8 \\
\hline Medical Health Legislation (20) & 40.0 & 13.6 & $60.0^{\mathrm{bl}}$ & 9.7 & 61.2 & 10.2 & $74.4^{\mathrm{bl}}$ & 11.9 \\
\hline Etc. ${ }^{\text {e) }}$ (32) & 30.9 & 6.0 & 35.0 & 8.4 & 46.5 & 10.3 & $52.0^{\mathrm{bl}}$ & 8.7 \\
\hline Total score (400) & 39.1 & 7.0 & $44.6^{b l}$ & 8.5 & 62.6 & 6.0 & $72.4^{\mathrm{bl}}$ & 5.3 \\
\hline
\end{tabular}

NK: North Korea, SK: South Korea, SD: Standard deviation.

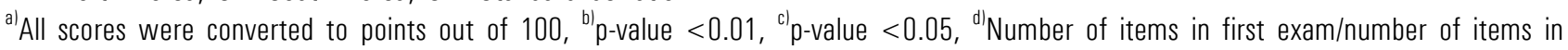

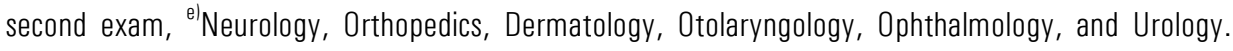


Table 3. NK Doctors' Challenges and Fruits for KMLE since the Year 2013

\begin{tabular}{ccccccc}
\hline Sex & $\begin{array}{c}\text { Age } \\
\text { (yr) }\end{array}$ & $\begin{array}{c}\text { Physician experience } \\
\text { year in NK }\end{array}$ & $\begin{array}{c}\text { Average total score } \\
\text { of } \begin{array}{c}\text { a) } \\
\text { examinations }\end{array}\end{array}$ & $\begin{array}{c}\text { Qualification test for } \\
\text { KMLE application }\end{array}$ & Year of passing KMLE & $\begin{array}{c}\text { Years required for } \\
\text { passing KMLE }\end{array}$ \\
\hline F & $30 s$ & 8 & 53.8 & Pass & 2014 & 7 \\
$F$ & $40 s$ & 19 & 50.1 & Pass & 2015 & 8 \\
$F$ & $20 s$ & 5 & 45.8 & Pass & 2015 & 4 \\
$F$ & $40 s$ & 15 & 42.3 & Pass & 2015 & 4 \\
$F$ & $50 s$ & 24 & 40.9 & Pass & 2016 & 11 \\
M & $30 s$ & 2 & 38.9 & Pass & 2016 & - \\
M & $30 s$ & 9 & 36.7 & - & - & - \\
M & $30 s$ & 9 & 35.9 & Pass & - & - \\
M & $50 s$ & 18 & 32.5 & - & - & - \\
$F$ & $40 s$ & 17 & 31.4 & Pass & - & - \\
\hline
\end{tabular}

NK: North Korea, KMLE: Korean Medical Licensing Examination, F: female, M: male.

${ }^{a)}$ All scores were average points between first and second preliminary examinations and converted to points out of 100 .

Fig. 1. Presumed Reasons for Extremely Lower Difficulty Index of NK Doctors than SK Medical Students among the 51 Selected MCOs

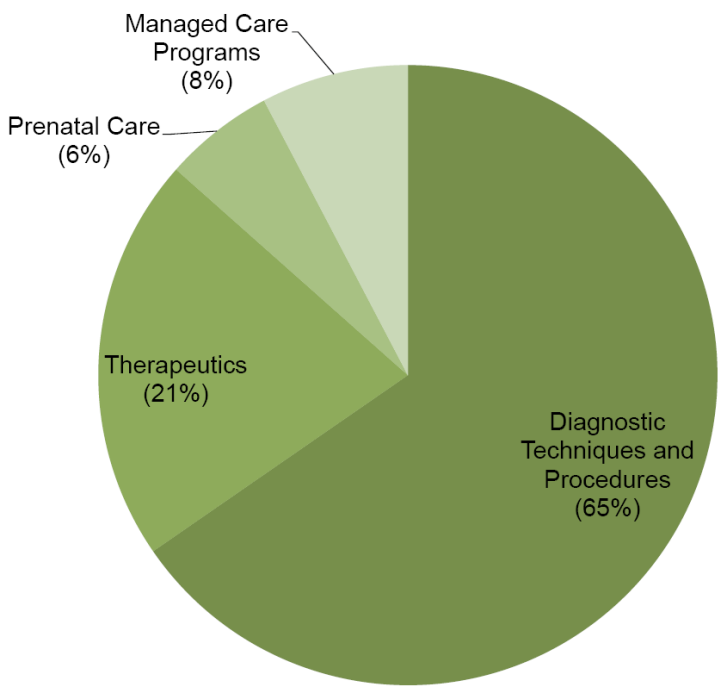

The number of multiple-choice-question (MCO) items of which difficulty indexes of North Korean (NK) doctors were lower than those of South Korean (SK) students by two times of the standard deviation of the scores of SK medical students was 51 151/800, $6.38 \%$ ). The group of NK doctors scored lower in those MCO items could be due to the lack of understandings for Diagnostic Techniques and Procedures, Therapeutics, Prenatal Care, and Managed Care Programs, respectively.

Of the eight doctors in the group of North Korean refugee doctors who passed the KMLE within the last 3 years after completing a "profession transition course for doctors," which started in 2013, six doctors obtained a medical doctor's license, showing a passing rate of $75 \%$ (Table 3).

The number of MCQ items of which difficulty indexes of North Korean doctors were lower than those of South Korean medical students by two times of the standard deviation of the scores of South Korean medical students was $51(51 / 800,6.38 \%)$. It has been suggested that the group of North Korean doctors scored lower in those MCQ items could be due to the lack of understandings for Diagnostic Techniques and Procedures, Therapeutics, Prenatal Care, and Managed Care Programs, respectively (Fig. 1).

\section{Discussion}

Unification of South and North Koreas which have kept different values and different styles of life for more than 70 years is coming into reality. In order to enable this unification to lead to stability and integration, as opposed to confusing and dividing the society, it is 
essential to restore a collapsed North Korea's health care system to establish the social security networks. In particular, it is important to establish medical security networks, for which existing medical facilities and professional staff should be able to be fully took advantage of [1].

The medical doctors in North Korea, the heart of North Korea's health care professionals, are known to be positioned to level 6 as soon as they graduate from medical school and gain advancement in their career to the upper level by passing an examination for promotion which is given every 3 years, but little is known about their clinical competency [5,7]. Park et al. [8] claimed that it usually takes about 12 years to reach level 3, which is equivalent to the consultant status in the United Kingdom or board-certified status in the United States; however, Lee [7] pointed out that procedures such as admission or promotion in medical schools in North Korea are neither disinterested nor rational. Moreover, a study of in-depth interviews of North Korean refugee doctors who earned a doctor's license in South Korea reported that there is a huge disagreement in the views on the capabilities of North Korean doctors between South and North Korean medical professionals [9].

Thus, in a situation of conflicting views on the clinical competency of North Korean doctors, the quantitative data such as scores of North Korean refugee doctors in the preliminary examination, and their challenges and achievements towards KMLE can be viewed as indirect proof for the clinical competency of North Korean doctors, upon which all medical professionals from both South and North Koreas have no other choice but to agree.

The scores of the group of North Korean doctors were improved in all subjects of the second preliminary examination, among which the scores of the subjects of General Surgery, Obstetrics and Medical Health Legi- slation were relatively higher than other subjects in the first examination, and they were improved in the second examination with a statistical significance (Table 2).

The scores of the group of North Korean doctors in the subject of Medical Health Legislation which deals with the medical system and laws of South Korea resulted in improved scores up to 60 -something points, a passing mark for KMLE as well as good scores in the first examination. This comes from the reason most of items were simple memorization-type questions compared with those of other subjects which were mainly problem solving-type questions (Table 2).

Surgery and Obstetrics showed a different pattern. A surgeon is known to be the most popular profession that North Korean medical students seek after, which is why most medical students painstakingly study on surgery. Therefore, the group of North Korean doctors is also likely to have experienced deep learning on surgery when they were students. For Obstetrics, due to the fact that most female doctors in the group of North Korean doctors experienced labor themselves, their understandings on this subject were thought to be higher than other subjects. That is, it is thought that a better understanding of the relevant subjects led to good scores in the first exam and improved scores in the second exam as well (Table 2).

For Pediatrics, the scores of the first exam was as low as 30-something points, but the average scores were improved most significantly in the second test. It is believed to be attributed to the special classes provided to the group of North Korean doctors after the first exam. A doctor who experienced both South and North Korean medical schools gave a total of seven special lectures on pediatric diseases, in which the lecturer, it was said, greatly enhanced the efficiency of memorization by using a vocabulary that could easily be understood only between the North Korean people. 
Meanwhile, the scores of Internal Medicine, Gynecology, and Psychiatry were relatively low in the first examination and the scores were improved in the second examination, which was not statistically significant.

For Internal Medicine, the scores of the first examination were poor, because, it is believed, it was difficult to raise the score in a short time frame due to the high amount of measure to study and for the same reason, score improvement in the second examination was thought to be insignificant.

For Gynecology and Psychiatry, due to the social atmosphere of prejudices prevailing in North Korea that a patient suffering from gynecological diseases is suspected as a sexually promiscuous woman or a psychiatric disease is recognized as a genetic disease, it is known that the number of patients who actually visit the hospital is very few, which might have led to a lack of clinical experience for the group of North Korean doctors and is thought to result in poor scores in the preliminary examinations.

The scores of Preventive Medicine in the group of North Korean doctors was less than $50 \%$ of the scores of the group of South Korean medical students in the first examination and this trend similarly continued into the second examination. This phenomenon can be attributed to the fact that there is a separate hygiene medicine department in North Korean medical schools which trains its "hygiene doctors" to mainly perform preventive services such as quarantine and vaccination, and for this reason, North Korean medical students who are to become "medical doctors" after graduation, tend to neglect this subject. Thus, it is believed that the poor scores of Preventive Medicine were caused by the fact that they did not study hard this subject at the stage of undergraduate education.

Meanwhile, the total scores of the group of South Korean medical students were shown to be improved in the second examination, which was taken a month before the KMLE, compared with those in the first examination, which was statistically significant (Table 2). Considering that the first and second preliminary examinations are usually similar in the level of difficulty and the curriculum of KNUSM ends after the first preliminary exam, the measurable clinical competency of the group of South Korean medical students by a written examination, can be considered to rise after first preliminary examination and approach full maturation stage just before the KMLE.

In contrast, although the total scores of the group of North Korean doctors did not reach the usual passing mark of the KMLE in both preliminary examinations, the total scores of the second examination was improved compared with the first examination, which was statistically significant (Table 2). In other words, this can be interpreted as follows: the clinical competency of the group of North Korean doctors also improved after first preliminary examination as shown in the group of South Korean medical students, but did not reach a stage of completion in order to pass the KMLE.

In fact, the 46 subjects belonging to the group of South Korean students in this study took the 78th KMLE and all passed, whereas of the eight subjects belonging to the group of North Korean doctors who were eligible to take the exam, six subsects finally obtained the medical doctor's license through the 78th, 79th, and 80th KMLEs (Table 3). This result is similar to the reported pass rate of $73 \%(8 / 13)$ of the KMLE from a study on training of North Korean Defector Physicians which was conducted by a hospital from 2009 to 2012 [10].

Interestingly, the higher the scores of the North Korean doctors in the preliminary examination, the faster they passed the KMLE (Table 3). The preliminary examination could be valued as a useful tool for measuring the clinical competency of North Korean refugee doctors at initial 
stage of preparing for KMLE. However, it should be kept in mind that the preliminary examination is, of course, a tool only evaluating the measurable clinical competency by a written test, and is unable to measure the actual clinical competency or long-term clinical experience of the examinee.

In the long run, at least 1 year or more is likely to be required, at a conservative estimate, for the clinical competency of the group of North Korean doctors to reach enough of a stage of maturation in order to pass the KMLE. The reasons why such a long time is required are as follows: they who learned medical terms as Latin in medical school need to adapt to the English medical terminology current in the Korean medical system, they need to understand modern diagnostic techniques and procedure and they need to understand therapeutics enabled by new technologies (Fig. 1).

In the process of replacing medical equipment and medications, which became scarce after the 1990s, a diagnosis by North Korean doctors was made solely based on a history taking and physical examination. Then, oriental medicine-based treatment was performed in parallel without first going through medical verification. And even though a medicine was prescribed under a correct diagnosis, the patient often was not able to buy the medicine for economic reasons, which made it difficult to expect them to be equipped with the same level of clinical experience as South Korean doctors.

Therefore, it is thought that except for basic medicine such as anatomy and physiology, North Korean refugee doctors need to receive such training as an integrated course for second grade medical students of KNUSM, in which diagnostic techniques and procedure, and therapeutics are taught about each human organ system. In addition, apprenticeship-style training for clinical practice, supervised by medical professionals, is considered to be necessary.
It is notable that those who passed the KMLE were mostly women, despite the fact that North Korean doctors were encouraged to enter and live in Hanawon except for the weekends to help them focus on their study without feeling the burden of daily life. Although a claim that women were more actively engaged was raised, another claim was also raised that two of four male North Korean doctors who failed the qualification test for KMLE application just before first preliminary examination could not focused on it. It seems that their motive of getting high marks in the exam was frustrated. Additional research is likely to be required.

This study is fundamentally limited in that it was targeted only to a limited number of North Korean refugee doctors, whose clinical capacities and difficulty indexes of MCQ cannot reflect those of all North Korean doctors representatively. Even though the authors arbitrarily chose 51 items that have different difficulty indexes between the two groups, it can be hard to accept the result as it is. Thus, more advanced analysis with enough number of North Korean doctors should be followed in the future.

Also, the practical test, which is another part of the KMLE, was not covered and we plan to conduct research on this part in the future. Throughout the entire study period, the group of North Korean doctors had to overcome challenges such as pressure on age and livelihood, educational and cultural differences between North and South Koreas, an unfamiliar form of MCQ type questions. These difficult situations acted like curtains to obscure the clinical competency of the North Korean refugee doctors. It should also be kept in mind that their capabilities can be properly assessed only when those curtains are drawn aside.

ORCID: Sung Uk Chae: http://orcid.org/0000-0002-6158-1182; 
Jeong Hee Yang: http://orcid.org/0000-0001-8646-6247;

Joon Seop Hyun: http://orcid.org/0000-0001-9529-4133;

June Hee Kim: http://orcid.org/0000-0002-0813-1465;

Seok Hoon Kang: http://orcid.org/0000-0002-2881-8774

Acknowledgements: Authors express our gratitude to Hanawon and Kangwon National University School of Medicine for their support for "profession transition course for doctors," in 2013, and also to Medical Education Assessment Consortium for their agreement on analyzing the scores of the preliminary examinations. Special thanks to the North Korean refugee doctors for their unparalleled endeavors for study.

Funding: None.

Conflicts of interest: None.

\section{References}

1. Shin YJ. Plan on establishment of post-unification North Korean medical safety net. J Korean Med Assoc 2013; 56: 394-401.

2. Yoon SJ. The experiences of system integration countries informing the potential unification of the Korean peninsula’s healthcare system. J Korean Med Assoc 2013; 56: 389-393.

3. Lee M, Kim H, Cho D, Kim SY. Overview of healthcare system in North Korea. J Korean Med Assoc 2013; 56:
358-367.

4. Association of American Medical Colleges. Physicians for the twenty-first century. The GPEP report: report of the panel on the general professional education of the physician and college preparation for medicine. Washington, DC, USA: Association of American Medical Colleges; 1984. p. 30-31.

5. Lee H. Plans for integrating health care personnel between the two Koreas. Korean Med Educ Rev 2016; 18: 1-15.

6. Kim MS, Kim CB, Cha BH, Park KC, Kwon SO, Shin KC, Lee HY, Kang SJ, Cha BS. A score of trial examination is closely correlated with a score of Korean Medical Licensing Examination 2002. J Educ Eval Health Prof 2004; 1: 87-98.

7. Lee YS. Medical education and certification of physicians in North Korea. Korean Med Educ Rev 2016; 18: 16-20.

8. Park KB, Roh YH, Lee-Park O, Park S. History of neurosurgery in Democratic People's Republic of Korea. World Neurosurg 2015; 84: 855-859.

9. Lee HK. Analysis on the actual state of North Korean health care workers and the integration plans in preparation for unification. Seoul, Korea: Ministry of Unification; 2014. p. 536-537.

10. Choi JP. The integration process of North Korean defector physicians into the South Korean medical system. J Korean Med Assoc 2013; 56: 383-388. 